cuffs in intubated patients. Anaesthesiology 42 : 637 (1975).

2. LoEser, E.A., STANLEy, T.H., JoRdan, W. \& MACHIN, R. Post-operative sore throat: influence of tracheal tube lubrication versus cuff design. Can. Anaesth. Soc. J. 27: 156 (1980).

3. Youngberg, J.A. Post-operative sore throat. Can. Anaesth. Soc. J. 27: 512, (1980).

4. Cozanitis, D.A. \& Tolvakka, E. A comparative study of glanthamine hydrobromide and atropine/neostigmine in conscious volunteers. Anaesthesist 20:416 (1971).

\section{EPIDURAL MORPHINE}

\section{DEAR SIR,}

It would appear that Doctors C. Hill, Chan and Tse (C.A.S.J. Vol. $29 \# 1,1982$ page 79) have failed to grasp the clinical significance of Dr. Wishart's efforts.

The patients in Dr. Wishart's series represent a specific group with inoperable terminal carcinoma and chronic intractable pain. He has offered (by way of informed consent) these persons a form of analgesia which permits them to remain at home in familiar and secure surroundings. In some cases, the patients have returned to work. Thus, these patients have continued to perform useful functions and to maintain their self-esteem and dignity.

What alternatives can we offer these patients? Should they be institutionalized for the sake of a rare complication in order to provide epidural narcotics? It is well known that large doses of intramuscular or oral narcotics result in significant clouding of consciousness and therefore an inability to relate effectively with one's immediate family and friends.

It is important to remember that anaesthetists are highly trained medical specialists, with expertise in the area of pain management. However, let us not forget that we are also physicians, hopefully with some degree of compassion and empathy for our fellow man.

$$
\text { D.W. Fear, M.D., F.R.C.P.(C) }
$$

John Holmes, M.D., F.R.C.P.(C) Peterborough, Ontario

\section{EPIDURAL MORPHINE}

SIR,

$$
\text { Re: Regional analgesic effect of epidural }
$$

As a member of the diminishing group which still holds that the postulate that narcotics injected intrathecally or extra-durally exert their primary effect at spinal cord level is far from proven, I was particularly interested by the article from Thompson, et al. in your November issue (p. 530). I found nothing in their account to alter my opinion.

Your contributors observed that, following the epidural injection of morphine in the lumbar region, the latency period before the onset of deep muscle ache following a "tourniquet test" was significantly greater in the leg than in the arm. Although Thompson, et al. do not remark upon it, I assume that the intensity of pain eventually appreciated in each involved limb was of the same order. Thus the effect of the morphine was not total analgesia but rather was relief from the more minor discomfort which preceded the peak intensity of pain caused by increasing ischaemia. The situation is, to me, highly reminiscent of the condition which I have termed the "epidural sieve" (Crawford, 1976). Examples of the latter are the acute pain of a placental abruption, or of a uterine rupture, experienced by the patient whose labour pains are concurrently totally relieved by an epidural. A similar situation is the severe backache associated with a persistent occipito-posterior position of the foetal head which even massive doses of bupivacaine injected into the epidural space by the lumbar and/or caudal route - fail to relieve, and which is probably due to direct pressure upon the lumbo-sacral plexus.

The pharmaco-physiological explanation of the "epidural sieve" lies, I believe, in the nerve fibre. I would find it very difficult to apply it, by analogy, to nerve cells within or without the spinal cord. Is it not conceivable that the morphine, of which a considerable mass in rather high concentration was deposited around the emergent lumbar roots, exerted a modicum of local anaesthetic type block at those sites, and thus delayed the onset of appreciation of pain by about 3-5 minutes? I do not intend to press this argument too far, but it appears to me to be equally as valid as that advanced by Thompson, et al.

J. Selwyn Crawford, F.F.A.R.C.S., F.R.C.O.G

Consultant Anaesthetist

The Birmingham Maternity Hospital Queen Elizabeth Medical Centre, Edgbaston, Birmingham B152TG England.

\section{REFERENCE}

Crawford, J.S. The epidural sieve and MBC (minimal blocking concentration): an hypothesis. Anaesthesia 3I: 1278-1280 (1976). 